\title{
The importance of structural inhomogeneity in GaN thin films
}

\author{
Z. Liliental-Weber ${ }^{1 *}$, \\ Roberto dos Reis ${ }^{1}$, Jan L.Weyher ${ }^{2}$, Grzegorz Staszczak, ${ }^{2}$ and Rafał Jakieła ${ }^{3}$ \\ ${ }^{I}$ Materials Science Division, Lawrence Berkeley National Laboratory, $\mathrm{m} / \mathrm{s}$ 62R203-8255, \\ Berkeley, CA 94720, USA \\ ${ }^{2}$ Institute of High Pressure Physic PAS, "Unipress", Warsaw, Poland \\ ${ }^{3}$ Institute of Physics PAS, Al. Lotników 32/46, 02-668 Warsaw, Poland \\ * Corresponding author: z_liliental-weber@lbl.gov
}

Keywords: A1- etching, structural defects, photoluminescence; A3-MOCVD; B1nitrides

\begin{abstract}
This paper describes two types of MOCVD-grown n-type GaN layers (Samples A and B) with similar carrier concentration but behaved differently under galvanic photoetching. In order to understand this behavior, Transmission Electron Microscopy (TEM) for cross-section and plan-view samples, Secondary Ion Mass Spectroscopy (SIMS) and photoluminescence (PL) techniques were applied. SIMS studies showed that $\mathrm{Si}, \mathrm{C}$ and $\mathrm{O}$ are approximately at the same concentration in both samples, but sample B also contained $\mathrm{Fe}$ and $\mathrm{Mg}$. Both GaN samples were grown on sapphire substrate with $\mathrm{Ga}$ growth polarity, which was confirmed by Convergent Beam Electron Diffraction (CBED). Despite a smaller layer thickness in Sample B, the density of edge dislocations is almost one order of magnitude lower than in Sample A. In addition, planar defects formed in this sample in the transition area between the undoped buffer and Si doped layers resulted in a substantial decrease in the density of screw dislocations at the sample surface. These planar defects most probably gave rise to the PL lines observed at $3.42 \mathrm{eV}$ and $3.32 \mathrm{eV}$. The new PL lines that only appeared in Sample B might be related to Mg impurities found in this sample. There were no detectable gettering of these impurities at dislocations using different diffraction conditions. However, Fe rich platelets were found only in Sample B due to the presence of $\mathrm{Fe}$ as well as hexagonal features, similar to defects reported earlier in highly Mg-doped GaN. These structural and chemical nonuniformities between the two GaN samples can explain their different etching behaviors. This paper demonstrates that samples with similar carrier concentrations do not necessarily ensure similar structural and optical properties and that additional material characterization are needed to ensure that devices built on such samples have similar performance.
\end{abstract}

\section{Introduction}

Applications of III-Nitrides in devices such as continuous wave (CW) lasers require low defect density material to ensure reliable operation at high current density. For this reason there is a large demand to develop bulk GaN crystals for homoepitaxial growth in order to eliminate misfit defects due to heteroepitaxy on foreign substrates. Among all growth methods hydride vapor phase epitaxy (HVPE) [1-3] is widely used to obtain thick layers with lower dislocation density that can be used as substrates for further homoepitaxial growth. However, in most cases, especially for the growth of 
layered structures in devices, metal organic chemical vapor deposition (MOCVD) [4-5] is used to grow GaN templates on sapphire substrates. Especially for this method it is important to use an appropriate characterization method, in order to have repeatable properties of templates for further growth of the subsequent layers. In many cases samples with similar carrier concentration are expected to show the same properties.

In this paper two Si-doped MOCVD GaN thin film samples grown on 2" sapphire substrate were studied using structural and optical methods. Sample A was cut from a commercial wafer. The details of the growth parameters were not available, except for the thickness of the layers and carrier concentration. This sample had a $4 \mu \mathrm{m}$ thick Sidoped GaN layers grown on a $3 \mu \mathrm{m}$ undoped GaN layer. Sample B was obtained from a scientific research center with the requirement that the carrier concentration should be $\sim 2 \times 10^{18} \mathrm{~cm}^{-3}$ similar to that of Sample A (both measured by Hall effect). Sample B has a $2.5 \mu \mathrm{m}$ Si-doped layer grown on a $0.42 \mu \mathrm{m}$ thick undoped layer, different than Sample A. It was expected that structural and optical properties of these samples are comparable, since only a small difference in carrier concentration of these samples was observed: $\mathrm{n}=$ $1.9 \times 10^{18} \mathrm{~cm}^{-3}$ for Sample A and $\mathrm{n}=3 \times 10^{18} \mathrm{~cm}^{-3}$ for Sample B. Preliminary defectselective etching revealed markedly different morphology of Samples A and B. Hence more detailed structural and optical studies were carried out on these samples.

\section{Structural and optical characterization}

\subsection{Galvanic photo-etching studies}

As it was reported earlier galvanic and electroless photo-etching in $\mathrm{KOH}$, called photo electrochemical (PEC) [6] and in $\mathrm{K}_{2} \mathrm{~S}_{2} \mathrm{O}_{8}+\mathrm{KOH}$ (KSO-D) etch [7] revealed dislocations and extended inhomogeneity in $\mathrm{GaN}$ [8]. It was also shown that using classical etching for Ga-polar GaN hetero-epitaxial layers (called orthodox etching), based on the chemical reaction mechanism, not only threading dislocations but also nanopipes can be revealed [8-11].

Galvanic photo-etching showed substantial differences between Sample A and Sample B. Sample A has etch whiskers of length equal to the etch depth that clustered into bunches, marked by $\mathrm{W}$ in Fig. 1a. Earlier studies showed that such whiskers are formed around dislocations propagating to the sample surface [7,12]. Etching of Sample B was not homogeneous and whiskers of different length were observed (Fig. 1b).

As it will be shown by TEM later much shorter protruding etching features were also observed between these long whiskers in both samples that were not associated with dislocations. This observation is in agreement with recently published results [13], which suggested that the short protruding dislocation-free etch features were related to nanoscale inhomogeneity.

Fig. 1. SEM images of GaN samples after galvanic photoetching in $\mathrm{KOH}-\mathrm{K}_{2} \mathrm{~S}_{2} \mathrm{O}_{8}$ solution. (a) Formation of long dislocation-related whiskers (W) in Sample A clustering in bunches; (b) Sample B showed a very non-uniform etching behavior. Bunching of whiskers was not observed.

\subsection{Secondary Ion Mass Spectroscopy studies}

Secondary Ion Mass Spectroscopy (SIMS) studies of two samples were performed on a CAMECA IMS6F system using a cesium $\left(\mathrm{Cs}^{+}\right)$primary beam, with the current kept at $400 \mathrm{nA}$. Several areas of the samples were studied and concentration profiles of dopants

and different impurities are shown in Figs. 2. Both samples show approximately the same 
concentration of $\mathrm{Si}\left(3 \times 10^{19} \mathrm{~cm}^{-3}\right), \mathrm{O}\left(3 \times 10^{17} \mathrm{~cm}^{-3}\right)$ and $\mathrm{C}\left(2 \times 10^{17} \mathrm{~cm}^{-3}\right)$. However, sample B also shows a high concentration of $\mathrm{Fe}\left(2 \times 10^{18} \mathrm{~cm}^{-3}\right)$ and some $\mathrm{Mg}\left(\sim 4 \times 10^{16} \mathrm{~cm}^{-3}\right)$ that are not observed in Sample A. The reason for the presence of Fe is not clear, but the presence of Mg may come from the so called "memory effect," in the growth chamber, since the same reactor was used to grow p-type $\mathrm{Mg}$ doped $\mathrm{GaN}$ samples.

Fig. 2. Si-dopant and impurities profiles as measured by SIMS on Sample A (a) and Sample B (b).

\subsection{Photoluminescence studies}

Low temperature (10K) Photoluminescence (PL) measurements were performed using the $325 \mathrm{~nm}$ line of a $\mathrm{He}-\mathrm{Cd}$ laser with a power density of about $5 \mathrm{~W} / \mathrm{cm}^{2}$ and a spot size diameter around $200 \mu \mathrm{m}$. PL results on these two samples show differences in peak position, peak intensity, and line broadening. Figure 3a shows the PL spectrum from Sample A, which is a relatively "clean" spectrum, similar to that of a typical highlydoped GaN sample. The PL line at $3.48 \mathrm{eV}$ is assigned to the near band edge luminescence while the line at $3.39 \mathrm{eV}$ is about the expected energy for the 1st phonon replica of the line at $3.48 \mathrm{eV}$. The line at $3.29 \mathrm{eV}$ is very close to the energy corresponding to the recombination involving electron from a shallow donor with a hole from a shallow acceptor, the so-called, shallow-donor/shallow-acceptor (SD-SA) recombination process. The high concentration of donors in this sample contributed to some broadening of the PL lines.

Fig. 3. $10 \mathrm{~K}$ PL spectra measured on Samples A and B shown in (a) and (b) respectively. Measurements were done in several sample areas denoted as p1, p2 and p3.

In contrast, the PL spectrum of Sample B shows marked differences from that of A and is quite complicated in nature (Fig. 3b). Three high intensity peaks at $3.22 \mathrm{eV}, 3.30$ $3.32 \mathrm{eV}$, and 3.42-3.34 eV are observed, in addition to the near band edge luminescence at $3.49 \mathrm{eV}$ (slightly shifted from $3.48 \mathrm{eV}$ observed in Sample A most probably due to stress). As noted above, in addition to $\mathrm{C}$ and $\mathrm{O}$ that were also observed in Sample A, SIMS results also show the presence of $\mathrm{Fe}$ and $\mathrm{Mg}$ acceptors in this sample. The PL lines are quite broad and new bands appear, suggesting poor sample quality. The new line at $3.42 \mathrm{eV}$ is very close to the emission line associated with I1 basal plane stacking faults (BPSF) [14-15]. There are different interpretations of the remaining lines. The lines 3.32 $\mathrm{eV}$ and $3.22 \mathrm{eV}$ are labeled as $\mathrm{Y} 6$ and $\mathrm{Y} 7$ lines [16-17] since they resemble $\mathrm{Y}$ lines observed in II-VI compounds [18]. Shallow-donor and acceptor located at the GaN surface gives rise to the $\mathrm{Y} 6$ line at $3.32 \mathrm{eV}$. The line $\mathrm{Y} 7$ at $3.21 \mathrm{eV}$ was attributed to an exciton bound to some point defects trapped by stress field of the threading dislocations. However, the $3.32 \mathrm{eV}$ line was observed before by cathodoluminescence (CL) studies and it was assigned to a I2 basal stacking fault $[19,20]$. CL studies show also the emissions at $3.16 \mathrm{eV}, 3.20 \mathrm{eV}$ and $3.3 \mathrm{eV}$ in areas of the samples with structural defects, but not assigned to a particular defect. Reshchikov et al [21] suggested that the band at $3.30 \mathrm{eV}$ might be related to the transition from the conduction band to the $\mathrm{Mg}$ acceptor (e-A transition) and the peak $3.22 \mathrm{eV}$ could be a phonon replica of the above-mentioned transition. In our Sample B Mg is also present as an impurity with much lower concentration than that described in [21], but based on our TEM studies (described in the following section) we expect a non uniform $\mathrm{Mg}$ distribution with the possibility that 
some areas in the sample may have a much higher Mg concentration. Such interpretation would be in agreement with the PL spectra taken from several sample areas (p1-p3) confirming large non-uniformity of this sample and a possibility of the relation of these lines to Mg impurities. Already based on these SIMS and PL results and confirmed by TEM studies it is not surprising that the galvanic photo-etching of Samples A and B showed different results.

\subsection{Cross-sectional and plan-view TEM studies}

The structural quality of these samples was characterized using Transmission Electron Microscopy (TEM). JEOL 3010 and TEAM 0.5 microscopes in the Lawrence Berkeley National Lab, both with the acceleration voltage of $300 \mathrm{kV}$ were used for this study. Cross-sectional and plan-view TEM samples were prepared from Samples A and B using Allied High Tech Precision Polishers to mechanically decrease the sample thickness down to $0.05 \mu \mathrm{m}$. Remaining mechanical scratches were removed using Ar ion mill to obtain specimens with electron transparency and readiness for the observation in an electron microscope.

Samples A and B were checked if their growth polarity was the same, since different polarities can lead to different impurity incorporation and different structural defects. Convergent Beam Electron Diffraction (CBED) [22-26] of the [1100] pole at $300 \mathrm{kV}$ acceleration voltage were compared with computer-simulated CBED patterns for the same zone axis. Since (0002) and (0002) diffraction discs in CBED pattern have different intensity distribution for the crystals without the center of symmetry, the direction of layer arrangement (Ga-N-Ga as [0001] Ga polarity or N-Ga-N [0001] N polarity) along the growth direction can be determined. CBED patterns were taken from different sample areas and with different sample thicknesses to ensure the accuracy of polarity determination. Comparison between experimental and simulated CBED patterns are shown in Fig. 4 (a-d). Based on these studies Ga growth polarity was determined for both samples.

Fig. 4. CBED studies of growth polarity of the Samples A and B; (a) A micrograph of the cross-section Sample A with the arrow indicating a growth direction. Sample B (not shown) had similar sample arrangement as the sample A; (b) Experimental CBED pattern from the Sample A for the sample thickness of $140 \mathrm{~nm}$; (c) Simulated CBED pattern for the same sample thickness and atomic arrangement shown in (d) and accelerating voltage of $300 \mathrm{kV}$ used for this study; (e) Sample B experimental and (f) simulated CBED patterns with thickness of $90 \mathrm{~nm}$. Matching of the experimental and simulated patterns confirm that both samples were grown with Ga polarity.

Cross-section TEM samples were prepared from Samples A and B, etched and nonetched. In both cases the etched samples showed large number of etched whiskers (Figs. 5 and 6). Low magnification micrographs of Sample A are shown in Fig. 5a and 5b. Long whiskers shown as $\mathrm{W}$ on (Fig. 1a) are also visible and are marked in Fig. 5a. They usually broke during preparation of a cross-section TEM samples. Some shorter whiskers are also formed between the longer whiskers, not observable in Figs. 1a and 1b, due to much lower resolution of the SEM. These figures show that not all whiskers are associated with dislocations.

TEM analysis of Sample A (both etched and non-etched) showed that dominating defects are edge dislocations with a density of $1.4 \times 10^{9} \mathrm{~cm}^{-2}$, while densities of screw and 
mixed dislocations at the sample surface are much lower and are $2.6 \times 10^{8} \mathrm{~cm}^{-2}$ and 1.2 $\mathrm{x} 10^{7} \mathrm{~cm}^{-2}$, respectively. On the other hand the density of all etching whiskers is over two orders of magnitude higher $\sim 2.2 \times 10^{10} \mathrm{~cm}^{-2}$.

Fig. 5. TEM images of photo-etched Sample A in cross-section taken close to the [0110] zone axis showing whiskers formation at the etched surface with screw dislocations indicated in (a) with [0002] diffraction vector (inset) and edge dislocations in (b) taken with [2110] diffraction vector (inset). Note the much higher number of etched whiskers than the total number of dislocations. Long whiskers (usually breaking during sample preparation) marked earlier as W on (Fig. 1a) are also visible in (a).

The total density of etching whiskers in Sample B was similar to that of Sample A. However, the density of screw and mixed dislocations (Fig. 6a) in this cross-section sample is practically negligible above the distance of approximately of $0.4 \mu \mathrm{m}$ from the interface, but the number of edge dislocations (Fig.6b) propagating through the entire layer is estimated to be $\sim 4 \times 10^{8} \mathrm{~cm}^{-2}$. This is a surprising result since this sample was much thinner, compared to Sample A. Usually increased sample thickness allows dislocation interaction leading to a lower dislocation density. In this sample screw dislocations were formed at the interface with the substrate, but they were intercepted by stacking faults (described in the next paragraph) formed in the transition area between undoped and Si doped layer.

The number of whiskers in both samples are comparable, suggesting that the presence of $\mathrm{Fe}$ and $\mathrm{Mg}$ in Sample B does not appear to influence the formation of these whiskers. This is in agreement with the recent study by Weyher at al [13], which also reported two orders of magnitude higher density of etching whiskers than dislocations. They attributed the formation of shorter whisker to "the non-uniformity in nano-scale distribution of native point defects, such as $\mathrm{V}_{\mathrm{Ga}}, \mathrm{O}_{\mathrm{N}}$ and related $\mathrm{V}_{\mathrm{Ga}}-\mathrm{O}_{\mathrm{N}}$ complexes". However, we note that it would be rather difficult to detect such nano-scale nonuniformity by TEM.

As is shown in Fig. 6a planar defects (stacking faults marked as SF) were formed in Sample B approximately at $0.4 \mu \mathrm{m}$ from the interface, at the transition region between the undoped and Si doped part of the GaN layer. One of these planar defects is shown in high resolution in the [2110] projection in Fig. 6c. This planar defect represents a low energy I1 type stacking fault [14,27] delineated by partial dislocations marked by the arrows. The presence of these defects in this area of the sample turn out to be beneficial, since due to their mutual interaction they lead to the elimination of screw dislocations formed at the interface (Fig. 6a). Density of edge dislocation at the surface of Sample B is lower by almost one order of magnitude $\left(\sim 4 \times 10^{8} \mathrm{~cm}^{-2}\right)$ than that in Sample A $\left(\sim 1.4 \times 10^{9}\right.$ $\mathrm{cm}^{-2}$ ), despite a much thinner undoped and Si doped layer in this sample. It is not clear why this differences in edge dislocation density occurred since these samples were grown in different laboratories and initial growth procedures of the buffer layer were not revealed.

In a view of these TEM results, it is clear that the broad and high intensity PL lines in Sample B cannot be explained entirely by dislocations, since the dislocation density in this sample is lower than that in Sample A. However, there are some local inhomogeneities in the sample as observed in PL spectra obtained from different sample areas (Fig. 3b; areas p1, p2, p3). 
We can attribute the additional 3.42 and $3.32 \mathrm{eV}$ lines observed in the PL spectrum of Sample B to stacking faults shown in Fig. 6a and 6c, since similar PL lines were also found earlier to be related to stacking faults in GaN samples [14-15, 19].

Fig. 6. (a) TEM cross section micrograph of Sample B after galvanic photo-etching taken close to the [0110] zone axis, as in sample A, with $g=$ [0002] (inset) revealing the distribution of screw dislocations. Note the lack of screw (and also mixed) dislocations in the subsurface area, due to their interaction with the stacking faults (SF) formed at about $0.4 \mu \mathrm{m}$ from the interface; (b) Edge dislocations ( $\mathrm{g}=[2110]$ ) (inset) propagating through the entire layer. (c) High-resolution micrograph in the [2110] projection showing a low energy I1 stacking fault (SF) delineated by partial dislocations (marked by arrows).

Studying of dislocation contrast in Sample B with a different diffraction conditions did not revealed any gettering of impurities at these dislocations. High-resolution microscopy of dislocation cores was not performed since this is beyond the scope of this paper. However, cross-section studies of Sample B using Z-contrast microscopy in the Berkeley TEM 0.5 microscope with an acceleration voltage of $300 \mathrm{kV}$ revealed the formation of small platelets (Fig. 7a) that were not observed in Sample A. This suggests that the sample has a high density of lighter elements (darker contrast). Higher resolution imaging of these platelets (Fig. 7b) shows a perfect ordering where every second double plane of Ga-N pairs is replaced with a double plane consisting of different elements. These platelets are distributed randomly in the Si-doped layer.

Fig.7. (a) Low magnification $\mathrm{Z}$ contrast micrograph showing a platelet in Sample B. Dark contrast suggests the presence of light elements; (b) High resolution image in the [2110] zone axis of the same platelet showing a different structure compared to the matrix (some ordering).

In order to study the chemical composition, we carried out Electron Energy Loss Spectroscopy (EELS) measurements on these platelets. EELS results shown in Fig. 8 reveal a much higher intensity ratio of $\mathrm{N}$ to $\mathrm{Ga}$ signals within the platelet than in the surrounding matrix. The intensity ratio (measured after a background subtraction) of $\mathrm{N} / \mathrm{Ga}$ on the platelet was 1.55 compared to 1.42 in the matrix. Fe $\mathrm{K}$ line is also visible when the electron beam is placed on the platelet. The ratio of Fe/Ga on the platelet is 0.65 in comparison to 0.36 in the matrix. The presence of such structural as well as chemical inhomogeneity in Sample B will definitely influence photoluminescence properties and galvanic etching of this sample.

Fig. 8. EELS spectra after background subtraction on the platelet marked \#1 and off the platelet \#2. A white dot indicates the position of the electron beam during spectrum acquisition. Note insets confirming a higher intensity of Fe L2, L3 lines on this platelet.

Additional information about structural perfection of Samples A and B was obtained from plan-view TEM studies of non-etched samples. The density of dislocations in Sample A, as estimated from the [0001] plan-view micrograph (Fig. 9a) was $\sim 8 \times 10^{8} \mathrm{~cm}^{-2}$. This value is in a good agreement with those obtained from the cross-section TEM (1.43 $\left.\mathrm{x} 10^{9} \mathrm{~cm}^{-2}\right)$ and from the SEM $\left(1 \times 10^{9} \mathrm{~cm}^{-2}\right)$ measurements. The [0001] plan-view micrograph of Sample B (Fig. 9a) shows a lower density of dislocations of $1.8 \times 10^{8} \mathrm{~cm}^{-2}$, 
also in a good agreement with the values obtained from SEM $\left(5 \times 10^{8} \mathrm{~cm}^{-2}\right)$ and crosssection TEM $\left(\sim 4 \times 10^{8} \mathrm{~cm}^{-2}\right)$. Moreover, plan view studies of Sample B shows many areas with hexagonal shaped features (Fig. 9c) with density of $4.2 \times 10^{9} \mathrm{~cm}^{-2}-1.4 \times 10^{10} \mathrm{~cm}^{-2}$, much higher than the density of dislocations. On this figure one can see larger hexagonal features and dots that are edge-on dislocations.

Fig. 9. (a) TEM-plan-view micrograph in the [0001] projection showing dislocation distribution in Sample A; (b) and (c) show two areas of Sample B with dislocations and hexagonally shaped defects, respectively. Some edge-on dislocations in (c) appear as dots (marked by arrows).

Tilting of the plan-view samples confirm that these hexagonal features are inverted pyramids. The presence of such features would suggest either the formation of pinholes protruding through the sample surface [27-30] or pyramidal inversion domains similar to those formed in highly Mg doped GaN samples [27,31-35]. Such pinholes were observed earlier in samples with a high impurity density, especially with oxygen [28], where pinholes were formed not only at dislocations but also in dislocation free areas. Since both samples have high and comparable concentration of oxygen, as measured by SIMS, and that these hexagonal features are present only at certain areas in Sample B, they are unlikely to be pinholes.

It is also possible that these hexagons (embedded pyramids in cross-section) are nuclei of the etching whiskers. However, plan-view TEM of un-etched sample A did not show these hexagonal features, despite that whiskers were also formed in this sample after etching.

We further speculate that these hexagons might be related to the presence of $\mathrm{Mg}$, as found earlier in $\mathrm{GaN}: \mathrm{Mg}$ samples [27,31-35], although the $\mathrm{Mg}$ concentration is much lower $\left(\sim 4 \times 10^{16} \mathrm{~cm}^{-3}\right)$ in Sample B compared to samples described in the above references $\left(\sim 1 \times 10^{19} \mathrm{~cm}^{-3}\right)$. However, the non-uniform distribution of these hexagons may indicate that there are regions (in sub-micron size) with locally higher $\mathrm{Mg}$ in this sample that cannot be detected by SIMS.

We performed Energy Dispersive X-ray (EDX) spectroscopy studies of the plan-view samples on several hexagons and we persistently observed some enhancement of $\mathrm{Mg}$ signal when the electron beam is placed on the hexagons (Fig. 10) with intensity similar to those observed in the samples with high $\mathrm{Mg}$ concentration $\left(\sim 1 \times 10^{19} \mathrm{~cm}^{-3}\right)$. In the present samples and those observed earlier the Mg signal was small [31], due to the fact that $\mathrm{Mg}$ is decorating only pyramidal walls and it is not present in the entire volume of the pyramids. Therefore, we believe that although SIMS results indicate on the average much lower $\mathrm{Mg}$ concentration of $\sim 4 \times 10^{16} \mathrm{~cm}^{-3}$ in Sample B, there may be local regions with much higher $\mathrm{Mg}$ concentration giving rise to the non-uniform distribution of the hexagons. This is evident when comparing plan-view TEM micrographs taken from different areas of Sample B (Figs. 9b and 9c) showing these hexagons only in some areas of the sample.

This non-uniformity of $\mathrm{Mg}$ distribution would also explain some differences in PL spectra (points p1-p3) and the non-uniform galvanic etching behavior observed in this sample. It would also suggest the presence of the $3.30 \mathrm{eV}$ band in the PL studies, as a transition from the conduction band to the $\mathrm{Mg}$ acceptor, with the $3.22 \mathrm{eV}$ peak as a phonon replica of this transition [21]. 
Fig. 10. EDX spectra taken on one of the hexagon shown in Fig. 9c. The spectra were taken with the electron beam on and off the hexagon. The inset shows some intensity enhancement of $\mathrm{Mg} \mathrm{K \alpha}$-line (shaded area) when the electron beam is placed inside the hexagon close to its wall.

\section{Conclusions}

This study illustrates that samples with similar carrier concentration do not necessarily have the same structural and optical quality. Therefore, growth of the subsequent layers on top of them, needed for devices, most probably would lead to materials with different properties and eventually devices with different performance. Already galvanic photo-etching of these samples revealed non-uniform etching of Sample B despite practically identical carrier concentration with Sample A.

SIMS results show the presence of $\mathrm{Fe}$ and $\mathrm{Mg}$ only in Sample $\mathrm{B}$, in addition to $\mathrm{Si}$ dopant. $\mathrm{O}$ and $\mathrm{C}$ impurities are also present in both samples with similar distribution and concentration. The presence of Fe resulted in the formation of small Fe-rich platelets. We speculate that Sample B may have areas with high $\mathrm{Mg}$ concentration that are responsible for the formation of hexagonal features (inverted pyramids). EDX studies on several of these defects revealed persistently some enhancement of $\mathrm{Mg}$ present within the pyramid. The appearance on the $3.30 \mathrm{eV}$ band in PL spectra is consistent with the transition from the conduction band to the $\mathrm{Mg}$ acceptor, with its phonon replica at $3.22 \mathrm{eV}$.

The density of dislocations is higher in Sample A with dominating density of edge dislocations in comparison with screw and mixed dislocations. In Sample B the density of screw and mixed dislocations at the sample surface is almost negligible due to their interaction with low energy stacking faults formed in the area between undoped and $\mathrm{Si}$ doped layers. The study of dislocation contrast at different diffraction condition did not reveal impurity gettering at dislocations. Etching whiskers with comparable density were formed in both samples and their density was almost two orders of magnitude higher than dislocations.

Combining SIMS, PL and TEM results we can provide plausible explanations for the differences in galvanic photo-etching of the studied samples.

\section{Acknowledgments:}

This work is supported by the Director, Office of Science, Office of Basic Energy Sciences, Division of Materials Sciences and Engineering, of the U.S. Department of Energy under Contract No. DE-AC02-05CH11231. Use of the facility in the National Center for Electron Microscopy in LBNL, Berkeley, CA is greatly appreciated.

\section{References}

1. R.J. Molnar, W Gotz, L.T. Romano, N.M. Johnson, J. Cryst. Growth 178 (1997) 147.

2. K. Motoki, T. Okahisa, S. Nakahata, N. Matsumoto, H. Kimura, H. Kasai, K. Takemoto, K. Uematsu, M. Ueno, Y. Kumagai, A. Koukitu, and H. Seki, J. Cryst. Growth 237-239 (2002) 912.

3. H. Morkoc, Materials Science and Engineering R 33 (2001) 135.

4. J. T. Torvic, M. Leksono, J. I. Pankove, B. V. Zeghbroneck, H. M. Ng, and T. Moustakas, Appl. Phys. Lett. 72 (1998) 1371.

5. S. J. Pearton, in Optolectroni Properties of Semiconductors, ed. M. O. Monasherh (Gordon and Breach, Amsterdam, 1997) Vol. 2. 
6. C. Youtsey, L.T. Romano, I. Adesida, Appl. Phys. Lett. 73 (1998) 797.

7. J. L. Weyher, F.D. Tichelaar, D. H. van Dorp, J. L. Kelly, and Khachapuridze, J. Cryst. Growth 312 (2010) 2607.

8. J. L. Weyher, Cryst. Res. Technol. 47 (2012) 333-340 /DOI 10, 1002/crat 20110042.

9. J. L. Weyher, S. Lazar, L. Macht, Z. Liliental-Weber, R. J. Molnar, S. Muller, V. G. M. Sivel, G. Novak, and I. Grzegory, J. Cryst. Growth 305 (2007) 384.

10. G. Kamler, J.L. Weyher, I. Grzegory, E. Jezierska, T. Wosinski, J. Cryst. Growth 246 (2002) 21.

11. S. Lazar, J.L.Weyher, L. Macht, F.D. Tichelaar and H.W. Zandbergen, Eur. Phys. J. Appl. Phys. 27 (2004) 275.

12. J.L. Weyher, F.D. Tichelaar, H.W. Zandbergen, L. Macht, P.R. Hageman, J. Appl. Phys. 90 (2001) 6105.

13. J.L.Weyher, J. Smalc-Koziorowska, M. Bankowska, I, Dziecielewski, L. Marona and P. Perlin, J. Crystal Growth, 426 (2015)153.

14. R. Liu, A. Bell, F. A. Ponce, C. Q. Chen, J. W. Yang, and M.A. Khan, Appl. Phys. Lett. 86, 021908 (2005).

15. J. Mei, S. Srinivasan, R. Liu, F. A. Ponce, Y. Narukawa, and T. Mukai, Appl. Phys. Lett. 88, 141912 (2006).

16. M. A. Reshchikov and H. Morkoç, J. Appl. Phys. 97 (2005) 061301.

17. M.A. Reshchikov, J. Jasinski, Z. Liliental-Weber, D. Huang, L. He, P. Visconti, and H. Morkoc, Physica B 340 (2003) 440.

18. P.J. Dean, Phys. Stat. Sol. A 81 (1984) 625.

19. I. Tischer, M. Feneberg, M. Schirra, H. Yacoub, R. Sauer, K. Thonke, T. Wunderer, F. Scholz, L. Dieterle, E. Muller, and D. Gerthsen, Phys. Stat. Solidi B 248 (2011) 611.

20. D. Zakharov, Z. Liliental-Weber, B. Wagner, Z.J. Reitmeier, E.A. Ireble, and R.F. Davis, Phys. Rev. B71 (2005) 235334.

21. M. A. Reshchikov, G.C. Yi, and B. W. Wessels, Phys. Rev B 59 (1999) 13176.

22. Z. Liliental-Weber, C. Kisielowski, S. Ruvimov, Y. Chen, J. Washburn, I. Grzegory, M. Bockowski, J. Jun, and S. Porowski, J. Electron. Mater. 25 (1996) 1545.

23. Z. Liliental-Weber, J. Washburn, K. Pakula, and J. Baranowski, Microsc. Microanal. 3 (1997) 436.

24. Z. Liliental-Weber, M. Benamara, O. Richter, W. Swider, J. Washburn, I. Grzegory, S. Porowski, J. W. Yang, and S. Nakamura, MRS Proc. 512 (1998) 363.

25. J. L. Rouviere, L. L. Weyher, M. Seelmann-Eggerbert, and S. Porowski, Appl. Phys. Lett. 73 (1998) 668.

26. Z. Liliental-Weber, Y. Chen, S. Ruvimov, W. Swider, and J. Washburn, MRS Proc. 449, (1997) 417.

27. Z. Liliental-Weber, Jap. J. Appl. Phys. 53, (2014) 100205

28. Z. Liliental-Weber, S. Ruvimov, W. Swider, Y. Kim, J. Washburn, S. Nakamura, R. S. Kern, Y. Chen, and J. W. Yang, MRS Proc. 482 (1997) 375.

29. Z. Liliental-Weber, Y. Chen, S. Ruvimov, and J. Washburn,Phys. Rev. Lett. 79 (1997) 2835.

30. Z. Liliental-Weber, Jap. Soc, Electr. Microsc. J. Electr. Microsc. 49 (2000) 339.

31. Z. Liliental-Weber, M. Benamara, J. Washburn, I. Grzegory, and S. Porowski, Phys. Rev. Lett. 83, (1999) 2370.

32. Z. Liliental-Weber, M. Benamara, J. Washburn, I. Grzegory, S. Porowski, D. J. H. Lambert, C. J. Eiting, and R. D. Dupuis, Appl. Phys. Lett. 75 (1999) 4159. 
33. Z. Liliental-Weber, J. Jasinski, M. Benamara, I. Grzegory, S. Porowski, D. J. H. Lambert, C. J. Eiting, and R. D. Dupuis, Phys. Status Solidi B 228 (2001) 345.

34. M. Leroux, P. Vennegues, M. Benaissa, E. Feltin, P. DeMierry, B. Beaumont, B. Damilano, N. Grandjean, and P. Gibart, Phys. Status Solidi A 192, (2002) 394.

35. Z. Liliental-Weber, T. Tomaszewicz, D. Zakharov, and M.A. O'Keefe, J. Cryst. Growth 281 (2005) 125. 
Figure 1

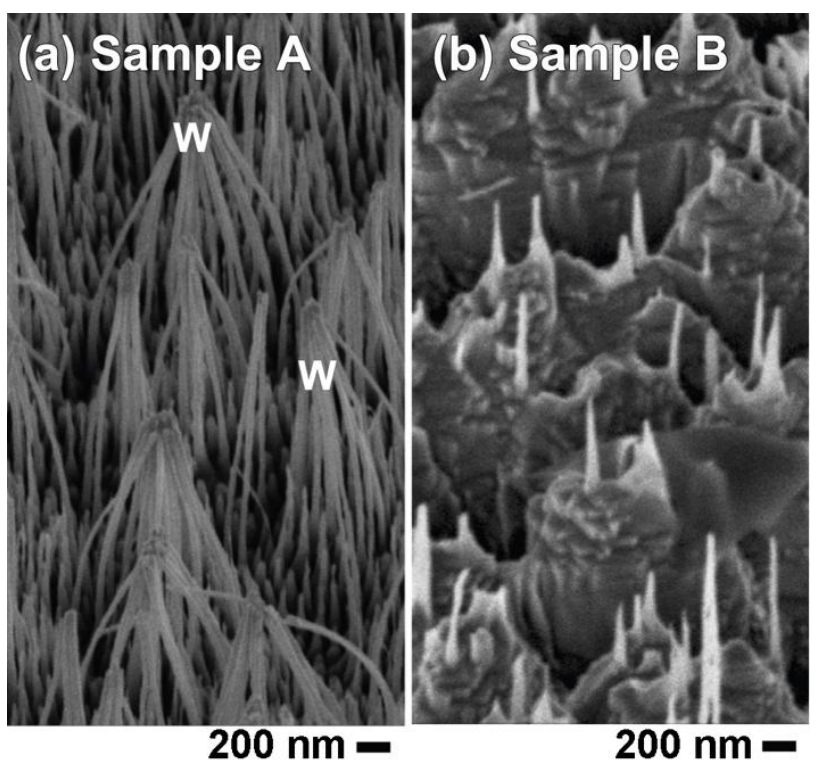

Figure 2

Figure 3

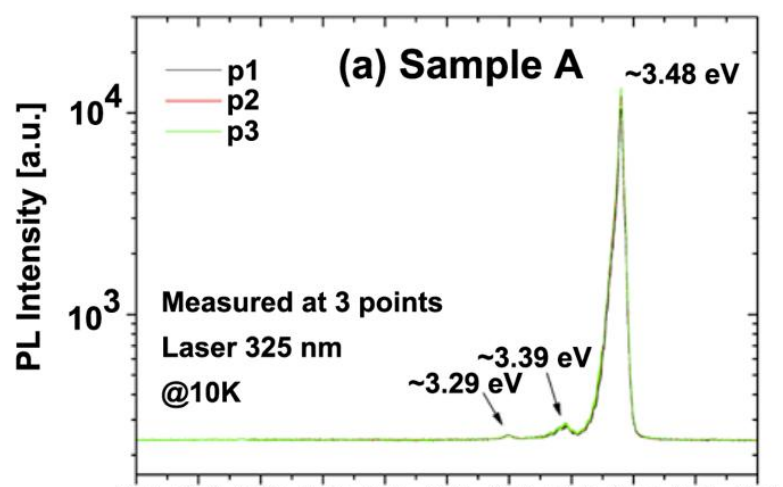

$\begin{array}{lllllllllll}2.7 & 2.8 & 2.9 & 3.0 & 3.1 & 3.2 & 3.3 & 3.4 & 3.5 & 3.6 & 3.7\end{array}$

Energy [eV]

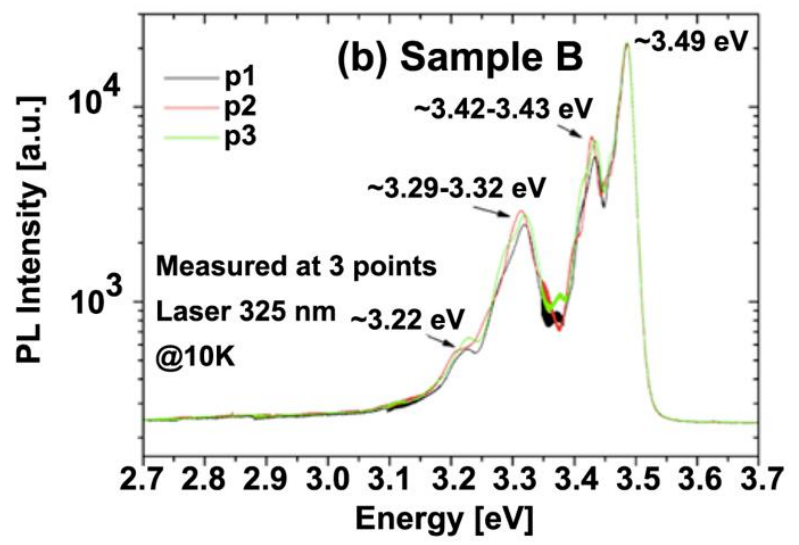

Figure 4
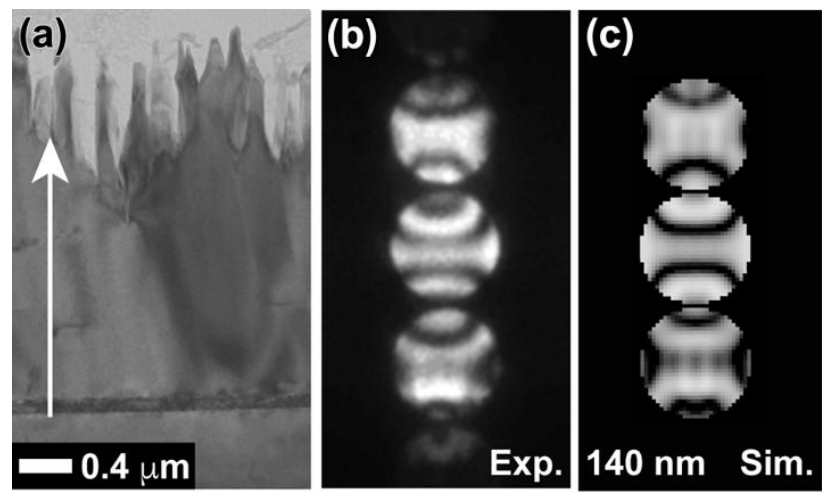

(d)
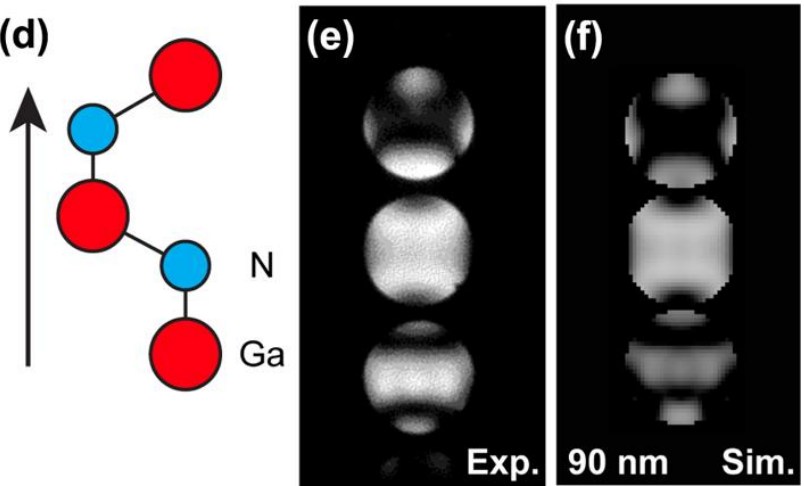
Figure 5

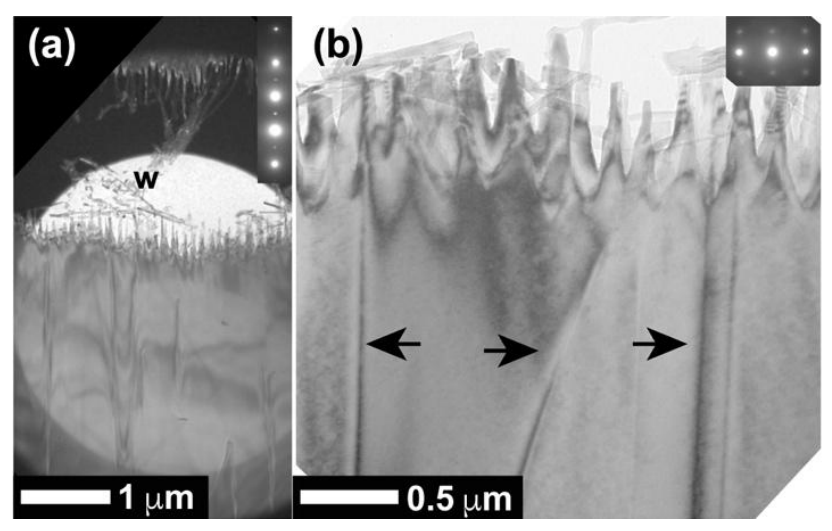

Figure 6
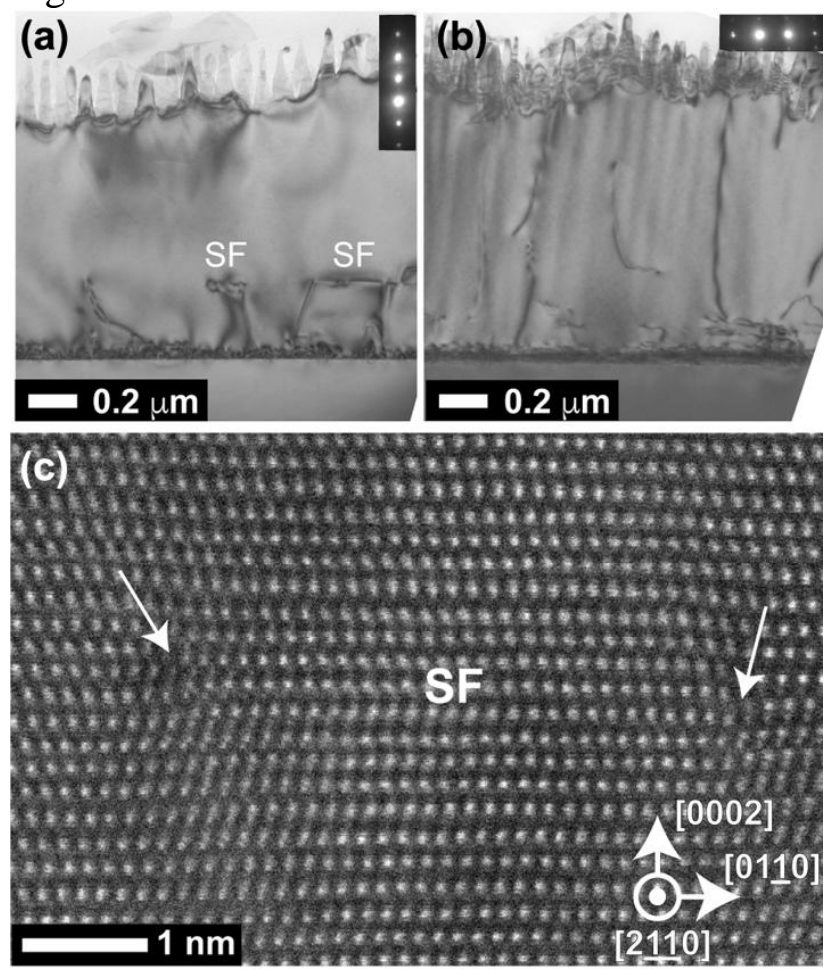

Figure 7

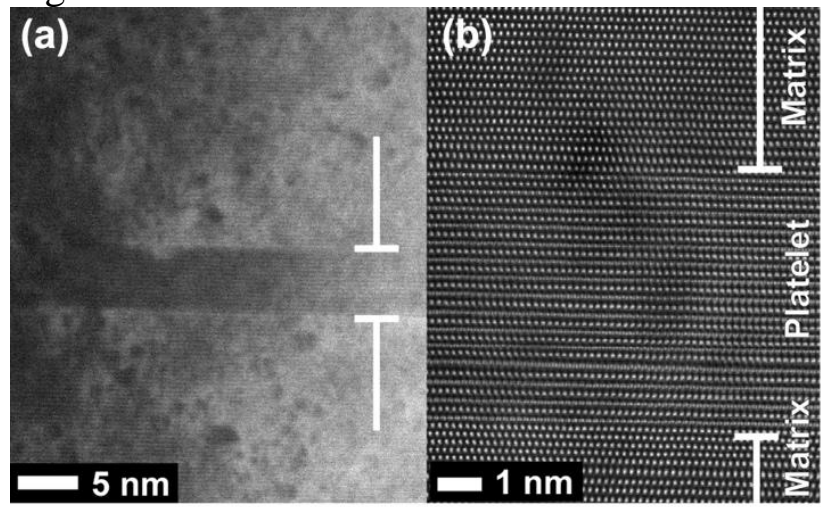


Figure 8
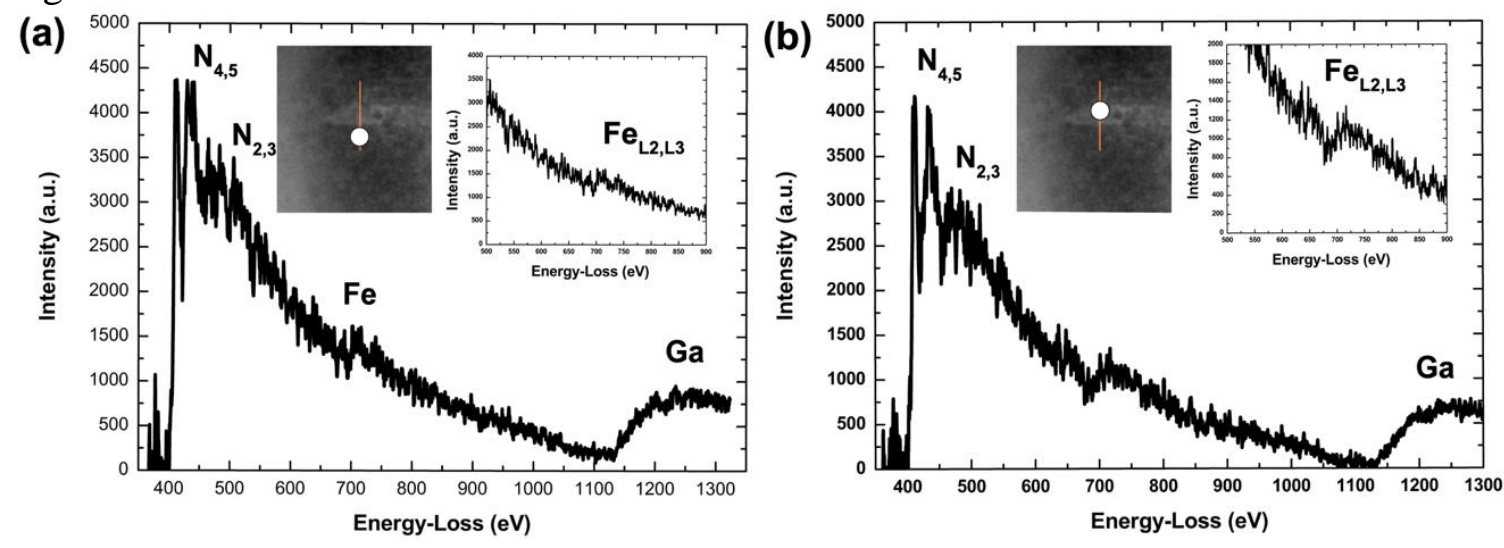

Figure 9
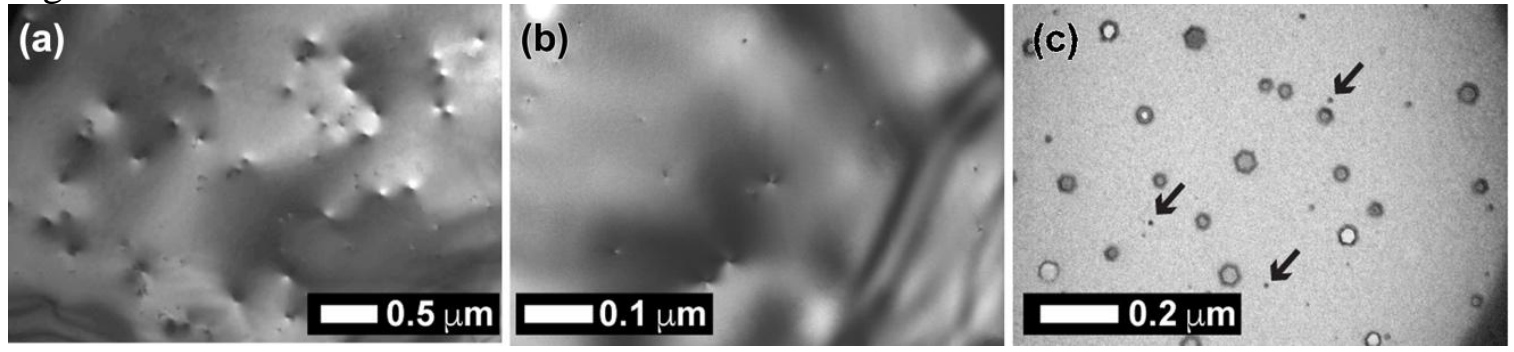

Figure 10:

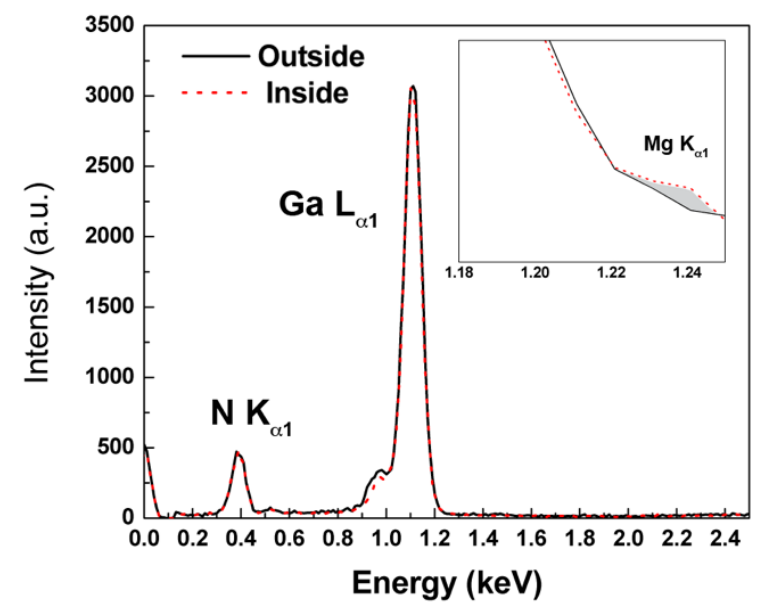

